\title{
BERM: the international forum for reference material producers and users
}

\author{
Mike Sargent
}

Published online: 10 February 2010

(C) Crown Copyright 2010

The 12th international symposium on biological and environmental reference materials (BERM 12), which was held at Keble College, Oxford, UK on 7-10 July 2009, continued a series which began in 1983 and has been held on a regular basis since then. The event originated as an informal gathering of interested scientists, particularly those working in Europe and the USA between which the meetings alternated every 2 or 3 years. More recently, BERM has been steered by a permanent committee comprising many of the major reference material producers and other key players. Asia has seen rapidly increasing interest in the field and the BERM 11 meeting was held in Japan. Hence, BERM 12 was a truly global forum which addressed the development of biological and environmental reference materials and their use in the calibration, validation and quality assurance of analytical measurements.

As with previous symposia, the scientific programme for BERM 12 encouraged discussion of issues ranging widely from novel methods for the manufacture and certification of reference materials to topics such as quality assurance and international harmonization. This special issue of ACQUAL focuses attention on some aspects of BERM 12 of interest to both the suppliers and the users of reference materials. The topics include undertaking stability studies, metrological traceability, approaches to certification, and the use of reference materials in proficiency testing. A reoccurring theme in these papers and many presentations at the symposium is the importance, to both reference material producers and users, of the guides and standards prepared by the ISO Reference Materials Committee, REMCO. Unfortunately, it is also apparent that several of the presently available documents lack clarity and give rise to confusion due, for example, to conflicting requirements between different guides.

Many of the delegates to ISO REMCO also participated in BERM 12 and should be aware of the issues. One reason for the present situation is the lack of discussion of new guidance with its potential users, such as those who attend BERM. The pages of ACQUAL would provide an ideal forum to obtain a broad church of views on key concepts before these documents are finalised. I hope that those concerned will use this and other possibilities to ensure that by the next BERM meeting in 2012 we have a coherent set of guides and standards which meet the needs of all concerned with reference materials. This will play a major part in achieving the ultimate goal of both BERM and ISO REMCO, namely improving the reliability of analytical data.

Mike Sargent Chairman, BERM 12 Scientific Committee

Guest Editor

M. Sargent $(\square)$

LGC Limited, Teddington, UK

e-mail: ms@lgc.co.uk 